NASA Technical Memorandum 89092

\title{
Structural Analysis of a \\ Bolted Joint Concept \\ for the Space Shuttle's \\ Solid Rocket Motor Casing
}

(NASA-TH-89092) STRUCTURAL ANALYSIS OF A

N88-12531

ECLTED JCINT CONCERT FCR THE SPACE SHUTTLE'S

SCLID ROCKEI MOTCE CASING (NASA) $8 \mathrm{p}$

$\begin{array}{lll}\text { CSCL 22B } & \text { UnClas } \\ & \text { G3/18 } & 0106515\end{array}$

Michael C. Lindell, and Winifred A. Stalnaker

September 1987

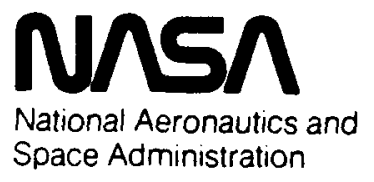

Langley Research Center

Hampton, Virginia 23665-5225 


\title{
STRUCTURAL ANALYSIS OF A BOLTED JOINT CONCEPT FOR THE SPACE SHUTTLE'S SOLID ROCKET MOTOR CASING
}

\author{
Michael C. Lindell * \\ and \\ Winifred A. Stalnaker + \\ Engineering Analysis Branch \\ NASA Langley Research Center \\ Hampton, Vircinia 23665
}

\begin{abstract}
The space shuttle challenger accident is thought to have been caused by the failure of one of the tang-clevis joints which join together the casing segments of the Solid Rocket Motors (SRM). Excessive displacement between the tang and clevis, possibly unseating the o-ring seals, may have initiated the resulting accident. An effort was undertaken at NASA's Langley Research Center to design an alternative concept for mating the casing segments. A bolted flanged joint concept was designed and analyzed to determine if the concept would effectively maintain a seal while minimizing joint weight and controlling stress levels. It is shown that under the loading condition analyzed the seal area of the joint remains seated. The only potential stress problem is a stress concentration in the flange at the edge of the bolt hole, which is highly localized. While heavier than the existing joint, this concept does have some advantages which make the bolted joint an attractive alternative.
\end{abstract}

\section{Introduction}

The design presented in this study is the product of months of design iterations and parametric studies on the behavior of bolted joints for this type of application. The parameters that were varied included the number and size of the bolts, the shape of the shell-tojoint transition, gusset thickness, flange thickness, and the of fset between the bolt centerline and the casing midsurface. Although the present design may not be fully optimized, it does represent a viable concept. Several other studies related to the analysis and redesign of the SRM casing joints can be found in the references listed at the end of this report.

Figure 1 shows a section of the SRM casing as it would appear with the proposed joint design. The present design and nominal dimensions are shown

\footnotetext{
* Aerospace Engineer, Systems Engineering Division

+ Mathematician,

Systems Engineering Division
}

in figure 2. The joint consists of 150 , 1 1/8-inch diameter studs, preloaded to approximately 707 of their ultimate strength, with nuts on both ends. The studs are positioned vertically through mating one-inch thick flanges and recessed into the cylinder such that the bolt circle is about 0.4 inches inboard from the midsurface of the casing wall. The materials used in the analysis are D6AC steel for the casing, MP35N steel for the stud, and Inconel 718 for the nut. See table 1 for a summary of material properties.

To provide additional stiffness and, more importantly, to provide an alternate load path for the vertical load in the casing, gussets are located between each of the studs. To prevent propellant gas from escaping at the flange interface, two flange seal rings are proposed. It is currently planned for the innermost seal to be a 3/8-inch viton elastomer o-ring and the other seal to be a $3 / 8-i n c h$ Inconel 718 c-ring. This seal combination was chosen for its ability to seal the maximum expected gap and for its relatively low seating force requirement ${ }^{1}$.

The key to this concept being effective in sealing the joint is the inward offset of the studs from the casing wall. With the centerline of the studs being located radially inward of the casing's midsurface, a moment is induced (i.e.. couple is created by the casing's axial load and the stud load) which tends to rotate the flange so as to close or seal the joint. This moment more than counteracts the pressure loading which tends to open the joint. For the usual bolted exterior flange design, the axial load, as well as the pressure load, tends to open the joint near the seal. However, by locating the studs inboard, the tensile axial load can be utilized to actually close the joint in the seal region.

\section{Structural Analysis}

Figure 3 shows the finite element model that was used in the analysis along with the boundary conditions that were imposed. The finite element program used for the analysis was EAL ${ }^{2}$. To take maximum advantage of symmetry, a 1.2 
degree wedge was used which represents one-half of a one-bolt segment. In the vertical direction, a 28-inch long section of the shell measured from the flange interface was modelled. This height was chosen so the top of the model was sufficiently far from the flange so as not to be influenced by the presence of the bolted region. Symmetry conditions were imposed on both the zerodegree and the 1.2-degree faces such that no displacement could occur in the circumferential direction at these nodes.

The nodes on the stud at the flange interface were constrained in the axial (vertical) direction. Since nodes on the bottom of the flange must be free to lift off of the contact surface but are constrained in the bearing direction due to symmetry, an iterative approach was utilized to insure this condition was met. After each particular finite element run, the interface nodal reaction forces and displacements were inspected. Any node reporting a tensile force (i.e., the node would lift off of the contact plane if it were not constrained) had its constraint removed for the subsequent finite element run. similarly, any node reporting a negative vertical displacement (i.e., the node passed through the contact plane) had a vertical constraint imposed for the subsequent run. This procedure was repeated until only bearing reactions existed at the interface and no negative displacements existed. Thus all constrained nodes were in bearing and all unconstrained nodes had positive displacements off of the contact plane.

A preload of $81,900 \mathrm{lb}(1 / 2$ of $70 \%$ of ultimate strength) was applied to the half stud of the finite element model. This was input into the model by enforcing an initial strain condition on the shank section of the stud. The preload was verified by suming reactions of the stud nodes at the flange interface in the absence of all other loading. Vertical forces due to the seals ware applied in the grooves on the flange. The viton o-ring exerts a force of $50 \mathrm{lb}$ per linear inch and the Inconel $718 \mathrm{C}$ ring exerts a force of 450 ib per linear inch.

The loading condition analyzed in this report is associated with the SRM ignition stage. It consiats of an internal pressure of $1000 \mathrm{psi}$ acting over the entire inner surface of the model and the axial load produced by this pressure of $55,500 \mathrm{lb}$ acting on the top surface of the model (approximately $16.7 \times 10^{6}$ lb load acting over the full circumference). These loads are shown graphically in figure 4. It should be noted that the stud preload is, by design, approximately 50t in excess of the applied axial load.
Results and Discussion

As a means of verifying the finite element model, displacement and stress results in the far-field region of the model were compared with classical thinshell theory. This comparison is shown in table 2 .

Included in the results of this study are the following:

1) deformed geometry

2) displacement contours (footprint) of the flange

3) axial nodal stress contours

4) circumferential nodal stress contours

5) weight comparison with existing joint

Figure 5 shows the exaggerated deformation of the model under the applied loading. The radial displacement is 0.304 inches at the top end of the model and 0.209 inches on the bottom of the flange at the center of the stud.

Figure 6 shows the vertical displacement pattern on the bottom of the flange. The inside edge of the flange remains closed and the area around both seals essentially remains in bearing. (The maximum displacement on the outside edge of the flange is 0.004 inches, representing a 0.008 inch total gap. However, this gap is of no consequence since it is not in the seal region.) For comparison, the gap in the seal area of the original tang-clevis joint under the same loading is 0.024 inches $^{3}$.

Figures 7, and 8 show different views of the average nodal stress contours in the axial (vertical) direction. The maximum stress is seen to occur in a localized region toward the outer edge of the gusset ( $149 \mathrm{ksi})$ and in the shell transition area (132 ksi). The gusset stress is mainly due to the tensile load transferred into the gusset from the casing. The shell transition stress is primarily a bending stress arising from local bending of the shell (see figure 5 also).

Figures 9 and 10 show two views of the average nodal stress contours in the circumferential direction. The maximum stress is a local stress concentration occurring in the flange at the edge of the stud hole $(281 \mathrm{ksi})$. For comparison, the maximum tensile stress concentration in the original tang-clevis joint at the edge of the hole surrounding the pin is $249 \mathrm{ksi}^{3}$.

Results indicate that under the loading condition analyzed the joint remains closed. The one high stress concentration area that exists is in the flange at the edge of the stud hole, which is highly localized. Although this very small region of localized yielding is not thought to be a problem, a plastic 
analysis may be needed to determine if this stress concentration is a major concern. Table 3 gives a summary of maximum stresses in the model.

As stated earlier, this design is the culmination of many design iterations. In all preceding models there was a consistent tradeoff between the gap and the stress concentration in the outer portion of the gusset. For example, increasing the length of the transition between the shell and the joint tends to decrease the stress in the gusset. However, since load is taken. out of the gusset more load is then carried down the shell resulting in a smaller net moment across the flange, which would tend to produce a gap. Moving the bolt circle outward also reduces the stress in the gusset, but because this reduces the moment arm between the casing midsurface and the stud, stress reduction is at the expense of increasing gap.

Weight was also a major concern, Making the transition length longer would increase the weight. Models in which the number of studs was decreased (gusset thickness increased) or in which the flange thickness was increased showed minimal stress reduction but significant weight increase. Therefore, all preceding analysis seemed to indicate that in order to achieve an acceptable compromise between stress, gap, and weight, any candidate model should have the following features:

1) the transition between the shell and the joint should be as sharp as possible in order to create the largest moment across the flange for a given stud offset, and also to minimize weight.

2) the number of studs, gusset thickness and stud offset should be such that the gap is zero or negligible, and the gusset stress is acceptable.

The design presented in this study reflects the above considerations. Although the design may not be fully optimized it does represent a viable candidate for further evaluation.

In order to compare the weight of this joint with other joint models, weights will be stated as the weight in excess of that corresponding to a straight shell, using the full circumference and both sides of the joint. For a mean radius of 72.81 inches and a wall thickness of 0.479 inches, the weight of a straight shell per inch of height is $62 \mathrm{lb} / \mathrm{in}$. Table 4 shows weight comparisons between the original tang-clevis joint, a modification of that joint, and the present bolted joint concept.

\section{Condusion}

In summary, the results show that this bolted joint concept, although heavier than the existing joint, is a viable alternative to the present method of foining the SRM casing segments. Under the loading condition analyzed, the gap in the seal region remains essentially zero. Furthermore, no stresses, with the exception of the stress concentration at the edge of the stud hole, are excessively large. Some additional local tailoring is needed to produce a model giving positive margins of safety in all required areas. This concept also offers several advantages over the tang-clevis joint currently used. Due to its geometry it is more amenable to analysis and, therefore, more predictable. Machining complexity is reduced with the face seals used in the bolted concept because seal squeeze is determined by the depth of the groove only. Squeeze in the gland seals used in the tang-clevis joint is determined by the diameter of the tang, the diameter of the clevis and the depth of the groove in the clevis, thus increasing the machining complexity. The face seals are seated at installation and remain seated under load, whereas the gland seals depend on the pressure to seat them. For the bolted concept, there is little relative motion between the casing segments caused by shell dynamics. For the gland seal to be effective, however, it must be able to respond quickly to transients after taking a set. This can be a problem because of the viscoelastic nature of the seal material, especially at low temperatures. Thus, the face seals are less prone to leakage in a dynamic environment than the gland seals. These advantages should be considered when evaluating the penalty of increased weight.

\section{References}

1. "LaRC Conceptual Design of Solid Rocket Booster In-Line Bolted Joint", NASA TY 89046, December 1986.

2. Whetstone, W.D., EISI-EAI Engineering Analysis Language Reference ManualEISI-EAI, System Ievel 312, Engineering Information Systems, Inc., Aug., 1985.

3. Greene, W.H., Knight, N.F., Jr. and stockwell, A.E., "structural Behavior of the Space Shuttle SRB Tang-Clevis Joint", NASA TH 89018, Sept., 1986.

4. "Report of the Presidential Commission on the space shuttle Challenger Accident", Washington, D.C., June 6, 1986. 
5. Bartheleny, J.-F.M., Chang, K.J. and Rogers, J.L. Jr., "Structural Optimization of an Alternate Design for the Space shuttle Solid Rocket Booster Field Joint", AIAA Paper 87-0702-CP, Presented at the AIAA/ASME/ASCE/AHS 28th structures, structural Dynamics and Materials Conference, Monterey, CA, Apr. $6-8,1987$.

6. Dorsey, J.T., stein, P.A. and Bush, H.G., "Structural Design of an In-Line Bolted Joint for the space shuttle solid Rocket Motor Case Segments", NASA TM $89027,1987$.

7. Card, M.F. and Wingate, R.T. "Structural Behavior of Solid Rocket Motor Field Joints", AIAA Paper 87-0701CP, Presented at the AIAA/ASME/ASCE/AHS 28 th structures, structural Dynamics and Materials Conference, Monterey, CA, Apr. $6-8,1987$.

TABLE 1 - MATERIAL PROPERTY SUMMARY

\begin{tabular}{lccc}
\hline Property & D6AC & MP35N & Inconel 718 \\
\hline Ultimate strength & $195 \mathrm{ksi}$ & $273 \mathrm{ksi}$ & $265 \mathrm{ksi}$ \\
Yield strength & $180 \mathrm{ksi}$ & $263 \mathrm{ksi}$ & $215 \mathrm{ksi}$ \\
Modulus of Elasticity & $30 \mathrm{msi}$ & $33.9 \mathrm{msi}$ & $29.7 \mathrm{msi}$ \\
\hline
\end{tabular}

TABLE 2 - FINITE ELEMIENT MODEL VS. THIN-SHELL THEORY

\begin{tabular}{lrr}
\hline Description & Model $^{1}$ & Theory \\
\hline Radial deflection & $0.304 \mathrm{in}$ & $0.304 \mathrm{in}$. \\
Axial stress & $76,000 \mathrm{psi}$ & $76,000 \mathrm{psi}$ \\
Circumferential stress & $151,240 \mathrm{psi}$ & $252,000 \mathrm{psi}$ \\
\hline
\end{tabular}

1. Results at the top end of the model.

TABLE 3 - MAXIMUM STRESS SUMMARY

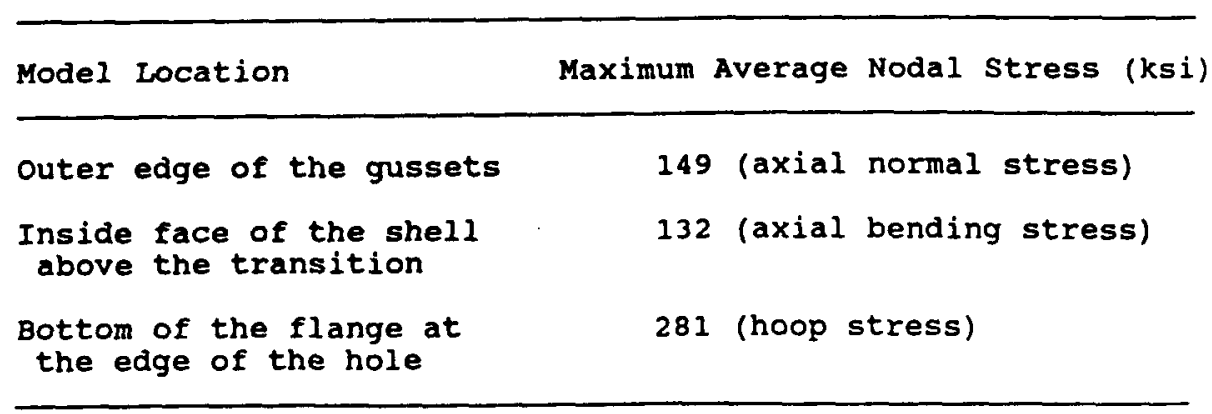


TABLE 4 - JOINT WEIGHT COMPARISONS

\begin{tabular}{lc}
\hline Joint Description & Weight in Excess of straight shell \\
\hline $\begin{array}{l}\text { original tang-clevis } \\
\begin{array}{l}\text { Tang-clevis with } \\
\text { capture feature }\end{array}\end{array}$ & $934 \mathrm{lb}$ \\
$\begin{array}{l}\text { Present bolted } \\
\text { joint concept }\end{array}$ & $1488 \mathrm{lb}$ \\
\hline
\end{tabular}

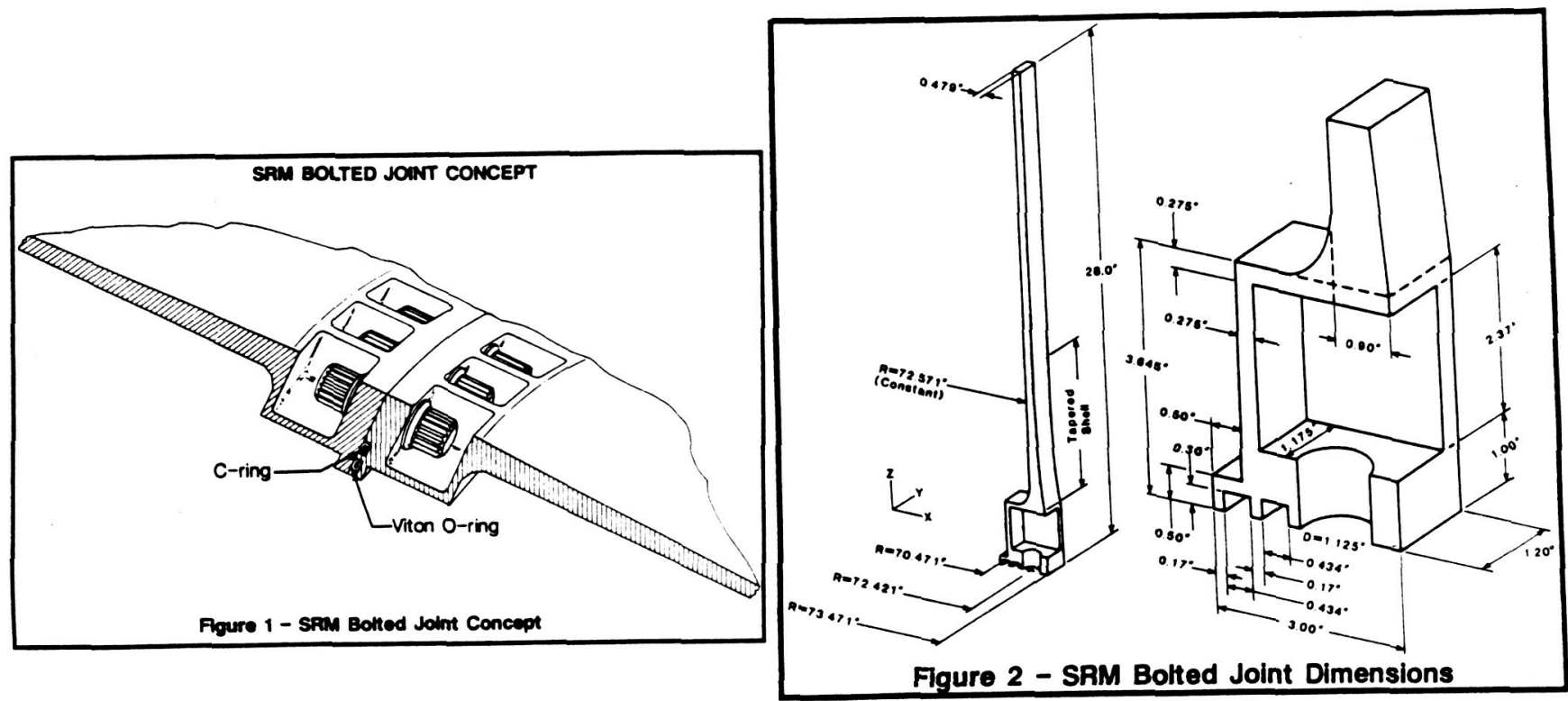

ORIGINAL PAGE IS

OF POOR NIAT ITY
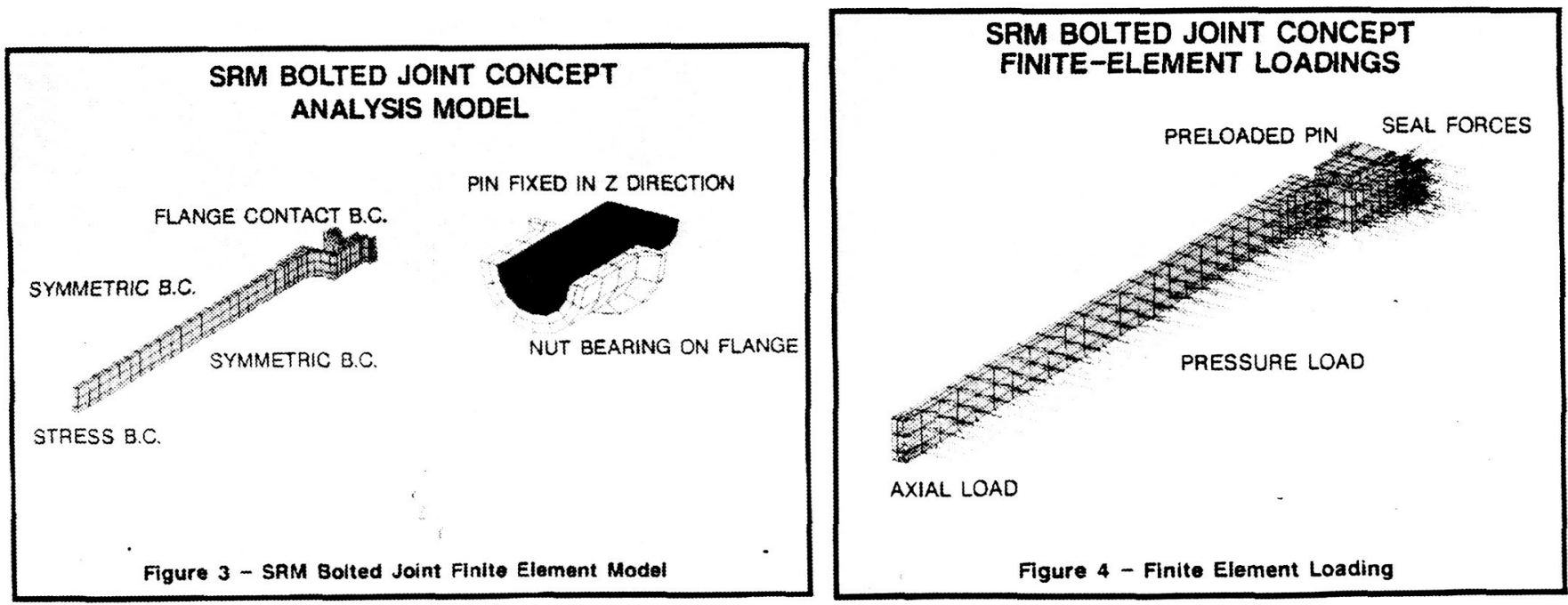

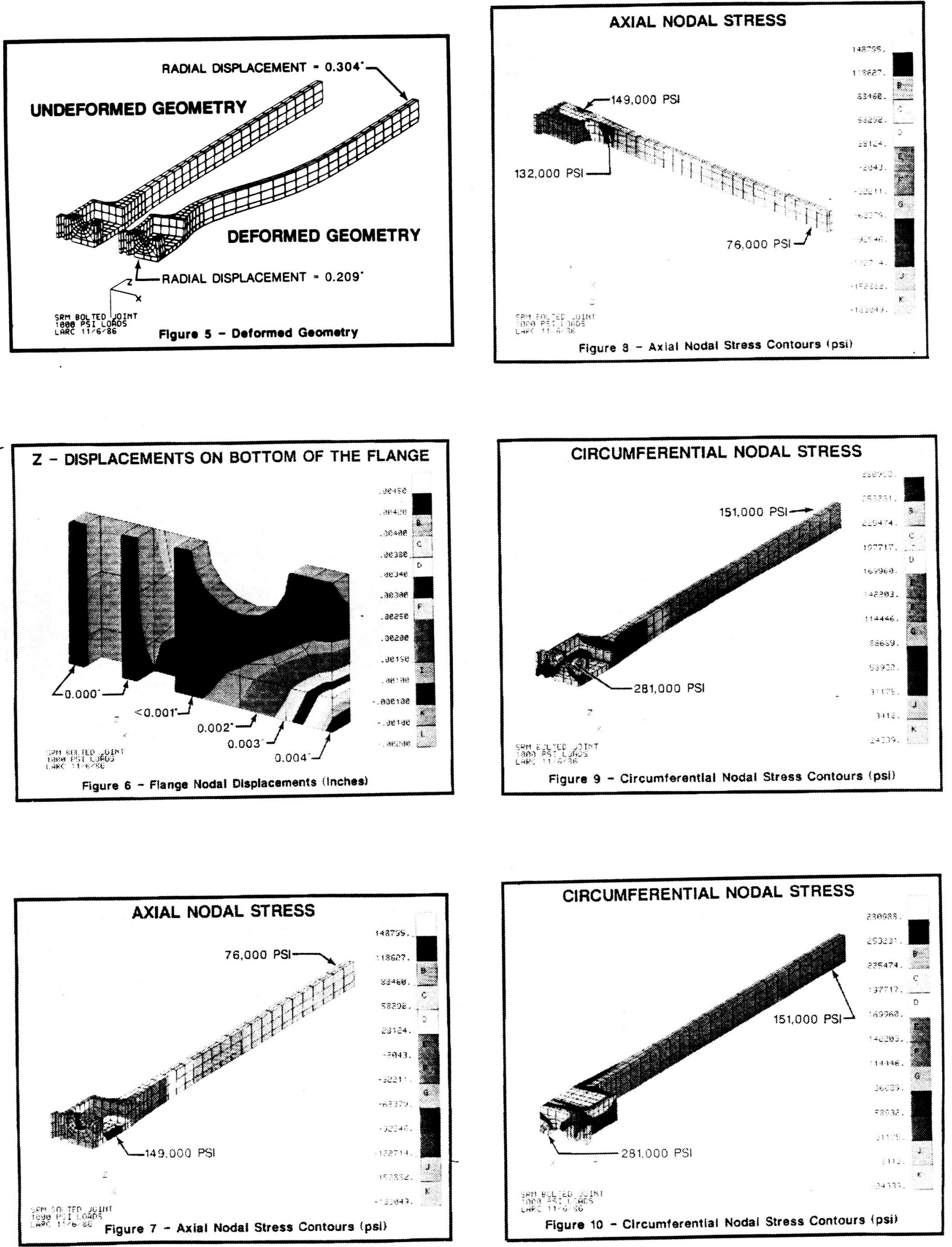


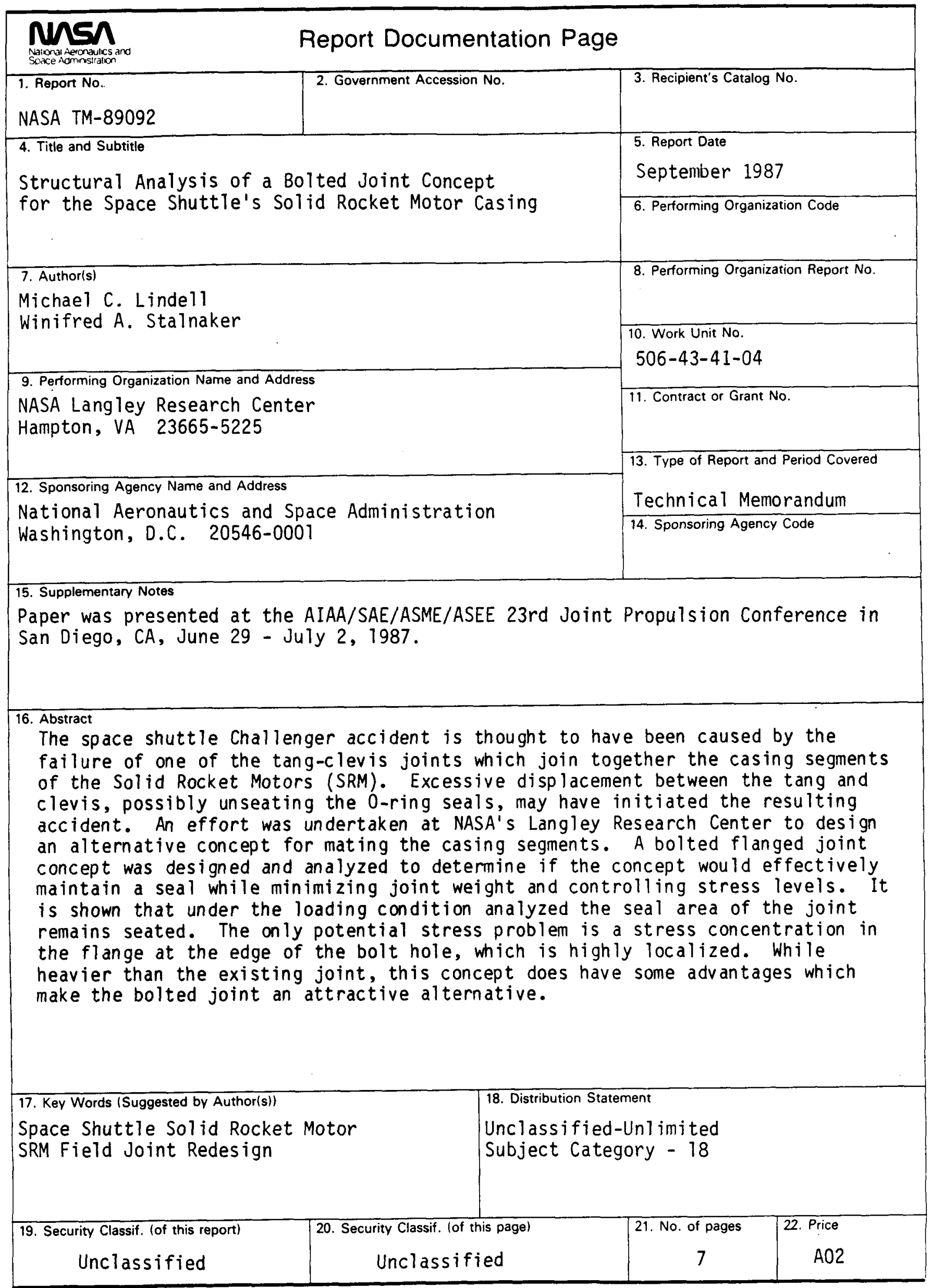

